\title{
Focus, Presuppositions, and Discourse Restrictions
}

\author{
Joachim Jacobs \\ University of Wuppertal
}

\section{Introduction}

In their stimulating paper Bart Geurts and Rob van der Sandt $(\mathrm{B} \& \mathrm{~V})$ argue that whenever focusing gives rise to a background $\lambda x[\varphi(x)]$, there is a presupposition to the effect that $\lambda[\varphi(\mathrm{x})]$ holds of some individual. This is their Background-Presupposition Rule (BPR). B\&V show that the BPR in conjunction with the binding theory of presuppositions yields an elegant analysis of the projection behaviour of background information, including a solution for the so-called requantification problem. In addition, the BPR offers answers to several questions concerning focus particles.

There are, however, other issues in the analysis of focus interpretation that $\mathrm{B} \& \mathrm{~V}$ do not discuss. In particular, they ignore the question how focus background structure (FBS) restricts discourse positions. It is one of the basic observations of traditional research on information structure that different FBSs of a sentence S correspond to different discourse positions of utterances of S. For example, the German sentence (1)

\section{Peter hat Gerda Geld geliehen \\ 'Peter lent money to Gerda'}

is a good answer to question (2) only if it has the FBS (3a), more precisely: only if its pronunciation is compatible with the subject being in focus and the rest of the sentence being in the background (the accent on $\mathrm{Pe}$ - indicates such a pronunciation very roughly ${ }^{1}$ ):

(2) Wer hat Gerda Geld geliehen?

'Who lent money to Gerda?'

(3) a. [Péter $]_{\mathrm{F}}$ hat Gerda Geld geliehen.

\footnotetext{
${ }^{1}$ A more precise account of the relation between focus position and accentuation is given in Jacobs (1991a).
} 


\section{b. Peter hat $[\text { Gérda }]_{\mathrm{F}}$ Geld geliehen.}

If a pronunciation is chosen that is incompatible with subject focus, as in (3b), (1) cannot be uttered as an answer to (2), regardless of the fact that the two pronunciations do not differ in propositional content.

This effect of FBS is not specific to question-answer pairs. It can also be observed in other types of discourse, e.g. in statement-contradiction pairs. To be used as a contradiction to statement (4),

\section{Klaus hat Gerda Geld geliehen. \\ 'Klaus lent money to Gerda'}

(1) again has to be pronounced as in (3a), i.e. with subject focus. ${ }^{2}$ Other choices of FBS, e.g. (3b), are odd.

A generalization covering these and many similar observations is

The Background-Discourse Rule (BDR):

If an utterance $u^{S}$ of a sentence $S$ has a free FBS that gives rise to a background $\lambda x[\varphi(x)]$, than $u^{S}$ is felicitous only if $\lambda x[\varphi(x)]$ has already been under discussion in the relevant stretch of discourse preceding $\mathrm{u}^{\mathrm{S}}$.

Some explanations: (i) A FBS is free if it is not associated with an overt operator, e.g. a focus particle or a negation word. (3a) and (3b), for example, are free FBSs. Non-free (or bound) FBSs may be subject to discourse restrictions that differ from the BDR, see Section 5 below. (ii) There are several ways in which $\lambda x[\varphi(\mathrm{x})]$ can be under discussion. Most obviously, $\lambda x[\varphi(x)]$ is under discussion if one of the interlocutors has asked of which entity $\lambda x[\varphi(x)]$ holds, or whether there is an entity of which $\lambda x[\varphi(x)]$ holds. Moreover, $\lambda \mathrm{x}[\varphi(\mathrm{x})]$ is under discussion if one of the interlocutors has asserted or denied a proposition equivalent to $\lambda x[\varphi(x)](e)$, for some entity e. (Similarly for other illocutionary acts involving $\lambda x[\varphi(x)]$.) Finally, $\lambda x[\varphi(x)]$ can even be under discussion in the relevant sense if one of the interlocutors shows non-verbal signs of having a propositional attitude roughly equivalent to a speech act of this kind, e.g. if she shows signs of asking herself of which entity $\lambda x[\varphi(\mathrm{x})]$ holds. (iii) The requirement that $\lambda x[\varphi(x)]$ be under discussion must be fulfilled within the close temporal

\footnotetext{
${ }^{2}$ In addition, the speaker is likely to say Nein ('No') at the beginning of an utterance of (1) in this context.
} 
proximity of $\mathrm{u}^{\mathrm{s}}$. How far this relevant stretch of discourse preceding $\mathrm{u}^{\mathrm{s}}$ can go back depends on several factors, among them the illocutionary type of $\mathrm{u}^{\mathrm{s}}$. If $\mathrm{u}^{\mathrm{s}}$ is a direct answer to a question $\mathrm{q}$, then the relevant stretch of discourse preceding $\mathrm{u}^{\mathrm{s}}$ only contains $\mathrm{q}$. In other cases, the relevant stretch of discourse may include earlier utterances in addition to the one immediately preceding $\mathrm{u}^{\mathrm{s}}$, provided that they are thematically related to $\mathrm{u}^{\mathrm{s}}$ and remain in the working memory of the interlocutors.

It is easy to see that the BDR accounts for the fact that (3a), but not (3b), can be used to answer question (2). The background of (3a) is $\lambda x[x$ lent money to Gerda], and this is exactly what is under discussion in (2). In contrast, the background of ( $3 b), \lambda x$ [Peter lent money to $x]$, is not under discussion in (2). Therefore the BDR is violated. (Remember that in the context of question (2) the relevant stretch of discourse preceding (3b) cannot be extended to include earlier utterances.)

What is the relation between the BDR and the BPR? I will consider three possibilities:

(A1) The discourse restrictions described by the BDR also follow from the BPR; therefore the BDR can be replaced the BPR.

(A2) The BDR and the BPR capture different aspects of the restrictions on the use of free FBSs in discourse; therefore, both rules are needed in an adequate theory of these restrictions.

(A3) For free FBSs, the BPR can be replaced by the BDR.

In Section 2, I will show that A1 is wrong: There are effects of the BDR that do not follow from the BPR. Therefore, a complete theory of the discourse restrictions induced by free FBSs cannot be based only on the BPR. As an alternative, A2 suggests itself. But this assumption does not seem to be correct either. I will show in Section 3 that certain predictions of the BPR about discourse positions of free FBSs are either incorrect or vacuous, depending on how much is attributed to accommodation. This entails that A2 is wrong, because if a rule makes incorrect or vacuous predictions about $X$, an adequate theory of $X$ shouldn't make use of this rule. - Given that the BPR does not seem to be of much use in the explanation of discourse restrictions on free FBSs, A3 must be considered as a further possibility. But in order to replace the BPR, the BDR must say something about the projection behaviour of free FBSs in complex sentences, e.g. in condi- 
tionals. I will argue in Section 4 that the BDR accounts for at least the most obvious restrictions governing the use of free FBSs in complex sentences if the relevant stretch of discourse (cf. above) may include first clauses of complex sentences.

The final section contains some very incomplete and tentative remarks on bound FBSs. I will present some evidence that neither the BPR nor the BDR alone could account for the wide variety of discourse restrictions on bound FBSs.

\section{The BDR cannot be replaced by the BPR}

Assumption A1 has some initial plausibility. Consider, for example, the data presented in Section 1 to motivate the BDR. The fact that answer (3b) to question (2) is odd could also be attributed to a violation of the BPR, because in the context of (2), the speaker normally cannot presuppose - i.e. take for granted - that the background of (3b), i.e. $\lambda x$ [Peter lent money to $\mathrm{x}]$, holds of some individual. At least (2) contains no indication that its speaker already believes $\exists x$ [Peter lent money to $x]$, and therefore, in the context of this question the speaker of ( $3 b$ ) does not seem to be entitled "to represent himself as assuming that the presupposition is already part of the common ground of assumptions that the interlocutors share between them" (Geurts 1999: 12). On the other hand, if (3b) is replaced by (3a), the BPR seems to be fulfilled, because question (2) implies ${ }^{3}$ that its speaker believes $\exists x[x$ lent money to Gerda]. Consequently, the speaker of (3a) can assume that the existential closure of the background $\lambda x$ [ $x$ lent money to Gerda] is part of the common ground, as required by the BPS. - Note that this result has been reached without reference to the BDR. Thus, if this example is representative of the general case, it seems that there is no need for the BDR if we adopt the BPR.

Unfortunately, the example is not representative. It is easy to find contexts in which a certain choice of FBS is odd because of a violation of the BDR although the existential closure of the background can be presupposed by the speaker. Consider FBS (5) of Peter hat Gerda eingeladen 'Peter invited Gerda':

\footnotetext{
${ }^{3}$ I use "imply" as a cover term for all kinds of inferences (entailments, presuppositions, conversational implicatures etc.).
} 
(5) cannot be uttered out of the blue, i.e. without any discussion of the background $\lambda x$ [x invited Gerda] in the preceding discourse. This is predicted by the BDR, and it holds regardless of whether the existential closure of the background is part of the common ground or not. Consider a situation where the $\mathrm{S}$ (peaker) and the $\mathrm{A}$ (ddressee) of (5) attend a party organized by Peter and Klaus. Since S and A know that uninvited guests are not admitted, they know that their friend Gerda, who is one of the persons they meet at the party, has been invited by one of the organizers. In this situation, $S$ can presuppose $\exists x[x$ invited Gerda], the existential closure of the background of (5). Consequently, an utterance by $\mathrm{S}$ of a sentence with a factive verb inducing this presupposition, e.g. Ich bin überrascht, daß Gerda eingeladen wurde 'I'm surprised that Gerda was invited', would be possible without additional requirements on the preceding discourse (provided its pronunciation is compatible with wide focus). In contrast, (5) couldn't be uttered out of the blue. Rather, even in this situation it would have to preceded by a piece of discourse between S and A which brings the background $\lambda x[x$ invited Gerda] into the discussion, for example a question or at least some non-verbal behavior of A indicating that she is wondering who invited Gerda. Otherwise, an utterance of (5) by $\mathrm{S}$ would be very strange. (It would probably lead A to ask herself what she has done to make $\mathrm{S}$ believe that she is interested in the question who invited Gerda.)

Thus, if a free FBS gives rise to a background $\lambda[\varphi(x)]$, it will not suffice that its existential closure can be presupposed. Rather, $\lambda[\varphi(x)]$ will have to be 'pre-discussed', in the sense of the BDR. Therefore, the BDR cannot be replaced by the BPR.

\section{Some problems with the BPR}

If the BDR cannot be replaced by the BPR, it is natural to assume (at least for adherents of the BPR) that the BPR and the BDR cover different aspects of the discourse restrictions on free FBSs and that an adequate theory of these restrictions therefore has to incorporate both of these rules. This is assumption A2, cf. Section 1. However, in order to be a legitimate part of a theory of the discourse behavior of free FBSs, the BPR must not make incorrect predictions about this behavior. Unfortunately, it seems that it does. Consider again example (5), repeated here for convenience: 
As we have seen, (5) can be uttered felicitously in a context in which the speaker presupposes $\exists x$ [x invited Gerda] (provided that the BDR is fulfilled). But the BPR leads us to expect that normally (5) can be uttered only if the speaker presupposes the background information. This prediction, however, is problematic in view of the fact that (5) can be used as an answer to question (6):

Hat irgendjemand Gerda eingeladen?

'Has anybody invited Gerda'

Clearly, (6) does not imply that its speaker A believes $\exists x$ [x invited Gerda]. Rather this question signals that A does not know whether this proposition is true. Thus, if S uses (5) as an answer to (6), she is certainly not entitled to assume that $\exists x$ [x invited Gerda] is already part of the common ground of assumptions she shares with A. In other words: In this situation, S cannot presuppose $\exists x[x$ invited Gerda $]$. Nevertheless, (5) is a perfect answer to (6).

Perhaps proponents of the BPR would deny that examples of this kind militate against the assumption that the BPR is an essential part of an adequate theory of free FBSs. Maybe they would assume that in such contexts the presupposition is accommodated and therefore doesn't have an effect on the acceptability of the utterance. ${ }^{4}$ But if accommodation is used to immunize the BPR against possible counterexamples like $(6) /(5)$ it is

\footnotetext{
4 "Perhaps" and "maybe", because B\&V do not discuss cases of this kind. However, one
} of their examples is similar to $(6) /(5)$ :

"(34) A: Who guessed the secret word?

B: Only [Wilma $]_{F}$ guessed the secret word."

$\mathrm{B} \& \mathrm{~V}$ point out that (34) is "a perfectly normal question answer sequence" in spite of the fact that A's question indicates that he doesn't know who guessed the secret word. They adduce this as support for their claim that the sentence uttered by B does not presuppose that Wilma guessed the secret word. Thus, B\&V obviously do not assume that the presupposition is accommodated to this context. - If this kind of argument against the assumption of a presupposition is sound then no accommodation should be assumed in the case of $(6) /(5)$ either. Rather, the fact that $(6) /(5)$ is a normal question answer sequence must be accepted as evidence against the claim that (5) presupposes $\exists x$ [x invited Gerda]. 
hard to see how this rule could explain how the choice of FBS could ever have an effect on the acceptability of utterances. Compare (5) and (7):

(7) Peter hat $[\text { Gérda }]_{F}$ eingeladen.

In contrast to (5), (7) cannot be used as an answer to (6). (If S produces (7) in the context of (6) se shows that she ignores the development of the discourse or lost track of it.) But this cannot be explained by the BPR if accommodation is allowed. In the context of (6) the speaker of (7) certainly cannot presuppose the background information $\exists x$ [Peter invited $\mathrm{x}$ ], but if the presupposition $\exists x$ [x invited Gerda] of (5) can be accommodated to this context, why shouldn't this be possible for the presupposition $\exists x[$ Peter invited $\mathrm{x}]$ of (7)?

Of course, under assumption A2 it is easy to account for the difference between (5) and (7). As an answer to question (6), (7) clearly violates the BDR while (5) doesn't. ${ }^{6}$ But then the BPR is simply not necessary in the explanation of discourse restrictions of this kind.

To sum up: For cases in which the background information of a free FBS cannot be presupposed, the BPR either makes wrong predictions or fails to differentiate between acceptable and unacceptable utterances, depending on how much is attributed to accommodation. Thus it is highly questionable whether an adequate theory of the discourse behavior of free FBSs should make use of the BPR.

\section{$4 \quad$ Can the BPR be replaced by the BDR?}

In spite of all these problems with the BPR, it cannot be denied that very often the speaker of an utterance $u$ with a free FBS takes it for granted that the background $\lambda x[\varphi(\mathrm{x})]$ holds of some individual. But even this can be explained by the BDR, because in the prototypical case the utterance preceding $\mathrm{u}$ that licenses the background in accordance with the BDR is a wh-

\footnotetext{
${ }^{5}$ Note that this even holds if both Gerda and Peter are persons that $\mathrm{S}$ and A are familiar with. In other words: The fact that (7) is impossible in the context of (5) has nothing to do with the use of a proper name in (7) that is not mentioned in (6).

${ }^{6}$ Remember that A2 says that both the BPR and the BPR are operative.
} 
question that implies that its speaker believes $\exists x[\varphi(x)],{ }^{7}$ thereby allowing the speaker of $u$ to take this proposition for granted.

All of these observations point in the same direction: An adequate theory of free FBS does not have to assume the BPR in addition to the BDR. However, if one wants to drop the BPR altogether in favor of the BDR, one must show that the BDR also handles the projection data adduced by B\&V as main evidence for the BPR. Unfortunately I cannot enter into a detailed discussion of the projection behavior of free FBSs in this short paper. So let me just give a rough sketch of how the BDR would deal with it. Consider (8) - (10):

(8) Wenn [Péter $]_{F}$ Gerda zu der Party eingeladen hat, dann wird sie sicher hingehen.

'If [Péter $]_{\mathrm{F}}$ invited Gerda to the party, then she will certainly come'

(9) Wenn meine Informationen richtig sind, dann hat [Péter $]_{\mathrm{F}}$ Gerda zu der Party eingeladen.

'If my information is correct, then [Péter $]_{\mathrm{F}}$ invited Gerda to the party'

(10) Wenn jemand Gerda zu einer Party einlädt, dann lädt [Péter $]_{F}$ sie ein.

'If someone invites Gerda to a party, then $[\text { Péter }]_{\mathrm{F}}$ invites her'

In contrast to $\mathrm{B} \& \mathrm{~V}$, I do not think that (8) and (9) induce the presupposition $\exists x$ [x invited Gerda]. Felicitous utterances of these sentences only require that the background has been under discussion in the preceding discourse. ${ }^{8}$ For example, both (8) and (9) are possible in the context of (11): ${ }^{9}$

\footnotetext{
${ }^{7}$ In Jacobs (1991b) I have argued that this a conversational implicature of wh-questions of the form 'For which $\mathrm{x}: \varphi(\mathrm{x})$ '.

${ }^{8}$ In addition, it is well known that the conditional operator in the semantic structure of such sentences is sensitive to the FBS of the protasis. Therefore the FBS of conditionals not only restricts their discourse positions but can also have an effect on their truthconditions.(I will ignore this in the following discussion.)

${ }^{9}$ (9) could be used as an (over-informative) answer to (11). (8) cannot be an answer, but could be combined with an answer to give additional information:
}

A: Weißt Du, ob Gerda zu der Party eingeladen wurde?

B: Nein, aber wenn [Péter $]_{\mathrm{F}}$ Gerda zu der Party eingeladen hat, dann wird sie sicher hingehen.

'No, but if [Péter $]_{\mathrm{F}}$ invited Gerda to the party, then she will certainly come' 
(11) Weißt Du, ob Gerda zu der Party eingeladen wurde?

'Do you know whether Gerda was invited to the party?'

Clearly in this context the speaker of (8) or (9) cannot presuppose $\exists x[x$ invited Gerda].

More generally it seems that the arguments of Sections 2 and 3 against the BPR also apply to complex sentences like (8) and (9): While some pre-discussion of the background is always required, it is not necessary that the existential closure of the background is part of the assumptions that the speaker can take for granted.

What about (10)? As predicted by the BPR, this sentence does not presuppose $\exists \mathrm{x}$ [x invited Gerda]. But in addition, the background information of (10) does not have to be under discussion either. Rather this sentence could be uttered, for example, as an elaboration of (12):

(12) Peter ist Gerdas einziger Freund.

'Peter is Gerda's only friend'

(12) does not pre-discuss $\lambda x$ [x invited Gerda]; nevertheless, no further utterances are necessary to license (10) in the context of (12).

This is predicted by BDR if, in the spirit of Stalnaker (1973), the stretch of discourse that has to be scanned for a pre-discussion of the background is allowed to include first clauses of complex sentences. More specifically, if the protasis of a conditional is among the utterances that can license the FBS of the apodosis by pre-discussing its background, then the FBS of (10) is licensed, because the protasis of (10) introduces the background $\lambda x[x$ invited Gerda] into the discussion.

Thus a Stalnakerian version of the BDR seems to able to account for the conditions restricting the use of free FBSs in complex sentences. Again the BPR is not needed.

\section{$5 \quad$ Some remarks on bound focus}

Without doubt, an FBS bound to (i.e. associated with) an additive focus particle gives rise to the presupposition that the background holds of some entity. For example, sentence (13) 
$[\text { Gèrda }]_{F}$ wurde áuch eingeladen.

'[Gerda $]_{\mathrm{F}}$ was invited, too.'

could not be uttered in a context like (14), in which the speaker of (13) cannot take it for granted that someone has been invited: ${ }^{10}$

(14) Weißt du, ob jemand eingeladen wurde?

'Do you know whether anyone was invited?'

Of course this does not follow from the BDR. This rule neither predicts presuppositions nor does it apply to cases of bound focus. The BPR, on the other hand, correctly predicts that (13) presupposes $\exists \mathrm{x}$ [x was invited]. But in view of the many problems with free FBSs (cf. above), this can hardly be interpreted as a confirmation of the BPR. Rather it shows that free FBSs and certain bound FBSs differ in respect to presupposed backgrounds. This is in contradiction to the BPR, because this rule leads us to expect that there aren't any differences of this kind.

In a localist (or relational) theory of focus it is not difficult to account for these differences. Additive focus particles are analyzed as reacting to the FBS in their scope by presupposing the existential closure of the background, ${ }^{11}$ whereas no such reaction is built into the analysis of other focus-sensitive operators, e.g. the illocutionary operators with which free FBSs are associated underlyingly according to the localist frameworks outlined in Jacobs (1988) and Krifka (1992).

Such a localist view on presupposed backgrounds does not entail that there aren't any restrictions that all kinds of FBS have in common. In particular, it leaves open the possibility that the BDR could be generalized to cover not only free but also bound FBSs, independently of the type of operator they are associated with. In fact, many observations show that the requirement that backgrounds be pre-discussed also holds for cases of bound focus. But there is at least one type of bound focus for which this requirement seems to be too weak:

\footnotetext{
${ }^{10}$ Note also that the presupposition of (13) cannot be accommodated to this context (cf. the discussion of accommodation in Section 3).

${ }^{11}$ In fact, B\&V's account of too comes very close to an analysis of this kind. - Other additive focus particles. e.g. even, and also some restrictive focus particles, e.g. merely, induce a further presupposition: They require the entity in focus to be in a certain position on a scale (i.e. on a contextually given ordering of the set of alternatives to the focus), cf. Jacobs 1983.
} 
(15) Nicht [Péter $]_{F}$ hat Gerda eingeladen.

Not

As soon as the focus is associated with an overt element that expresses replacive negation, ${ }^{12}$ pre-discussion of the background will not suffice. Rather, utterances of (15) require the whole proposition in the scope of negation, including the focus, to be at issue in the preceding discourse. In the typical case, (15) is a reaction to (16) but is hardly possible in the context of (17) (unless some prior utterance discusses whether Peter invited Gerda):

(16) Peter hat Gerda eingeladen.

'Peter invited Gerda'

(17) Gerda wurde eingeladen.

'Gerda was invited'

Thus it seems that more empirical research on the use of different kinds of bound FBSs in discourse is necessary before the BDR could be generalized to hold for all types of FBS.

\section{References}

Geurts, B., 1999: Presuppositions and Pronouns. Elsevier, Oxford.

Jacobs, J., 1983: Fokus und Skalen. Zur Syntax und Semantik der Gradpartikeln im heutigen Deutsch. Niemeyer, Tübingen.

Jacobs, J., 1988: Fokus-Hintergrund-Gliederung und Grammatik. In: H. Altmann (ed.), Intonationsforschungen. Niemeyer, Tübingen. 89-134.

Jacobs, J., 1991a: Focus Ambiguities. Journal of Semantics 8: 1 - 36.

\footnotetext{
${ }^{12}$ Replacive negation is a special negative construction which must not be confused with other constructions in which negation interacts with FBS, cf. Jacobs (1992).
} 
Jacobs, J., 1991b: Impikaturen und 'alte Information' in w-Fragen. In: M. Reis, I. Rosengren (eds.), Fragesätze und Fragen. Niemeyer, Tübingen. $201-222$.

Jacobs, J., 1991c: Negation. In: A. von Stechow/D. Wunderlich (eds.), Semantics. An International Handbook of Contemporary Research. Berlin/New York, de Gruyter. 560 - 596.

Krifka, M. (1992): A Compositional Semantics for Multiple Focus Constructions. In: J. Jacobs (ed.) Informationsstruktur und Grammatik. Westdeutscher Verlag, Opladen. 17 - 53.

Stalnaker, R. C. (1973): Presuppositions. Journal of Philosophical Logic 2: $447-457$. 